\title{
The new Era of non-Steroidal Mineralocorticoid Antagonists in Treating Heart Failure in Diabetic Kidney Disease Patients.
}

\author{
Eqerem Hasani ${ }^{1}$, Merita Rroji ${ }^{2 *}$, Myftar Barbullushi ${ }^{2}$
}

Received: 10 December 2021 / Accepted: 26 December 2021 / Published online: 20 January 2022

This article is published with open access at https://journal.astes.org.al

(C) The author(s) 2022. \& Copyright (C) 2022, the Albanian Society for Trauma and Emergency Surgery

(c) The Albanian Journal of Trauma and Emergency Surgery is an Open Access Journal. All articles are distributed under the terms of the Creative Commons Attribution Non-Commercial License: http://creativecommons.org/licenses/by-nc/4.0/) which permits unrestricted non-commercial use, distribution, and reproduction in any medium provided the original work is properly cited.

\begin{abstract}
Inappropriate activation of the mineralocorticoid receptor (MR) plays a significant role in developing hypertension, the development of cardiac pathological changes, and chronic kidney disease (CKD), where death related to cardiovascular (CV) causes is the primary competing for the outcome to the progress to end-stage renal disease (ESRD) in patients with CKD.

Congestive heart failure (CHF) is a frequent comorbidity in patients with CKD. MR overactivation within the heart might cause coronary endothelial dysfunction, myocardial apoptosis, and reactive myocardial fibrosis and thus contribute to cardiac remodeling and its adverse consequences.

MR antagonists (MRAs) are evidence-based therapy in symptomatic patients with heart failure and reduced ejection fraction (HFrEF). Finerenone, a novel, nonsteroidal, selective mineralocorticoid receptor antagonist (MRA) with anti-inflammatory and antifibrotic effects, is a promising tool in treating heart failure in patients with T2DM and CKD.

It is felt to have higher potency and less hyperkalemia than steroidal MRAs such as spironolactone and eplerenone. It is unclear and a matter of discussion if it could be first-line therapy in this group of patients.

Conclusion: Nonsteroidal MRAs are currently tested in clinical trials. Based on preclinical and first clinical data, these nonsteroidal MRAs might overcome the limitations of today's steroidal antagonists.

Keywords: mineralocorticoids antagonist, CKD, diabetic nephropathy, heart failure.
\end{abstract}

\section{Abbreviations}

Mineralocorticoid Receptor - MR; Finerenone \& Esaxerenone are two new nonsteroidal MR; Chronic Kidney Disease - CKD; Cardiovascular - CV; End-Stage Renal Disease - ESRD; Congestive Heart Failure - CHF; MR antagonists - MRAs; Reduced Ejection Fraction HfrEF; Mineralocorticoid Receptor Antagonist - MRA; Type 2 Diabetes Mellitus - T2DM; Aldosterone Antagonists

Original article, no submission or publication in advance or in parallel

\footnotetext{
* Corresponding author: Merita Rroji, MD, Ph.D.

$\bowtie$ meritarroji@yahoo.com,

1 Service of Emergency, University Hospital Center" Mother Tereza”, Tirana, ALBANIA.

2 Service of Nephrology, University Hospital Center" Mother Tereza", Tirana, ALBANIA.
}

- AAs; Randomized Aldactone Evaluation Study -RALES; Eplerenone Post-Acute Myocardial Infarction Heart Failure Efficacy and Survival Study - EPHESUS; Eplerenone in Mild Patients Hospitalization and Survival Study in Heart Failure - EMPHASIS-HF; AngiotensinConverting Enzyme inhibitors - ACE-I; Glomerular Filtration Rate - GFR; Renin-Angiotensin-Aldosterone System - RAAS; Excessive Extracellular Matrix - ECM; Reactive Oxygen Species - ROS; Nicotinamide Adenine Dinucleotide Phosphate - NADPH; Left Ventricular - LV; Finerenone in Reducing Cardiovascular Mortality and Morbidity in Diabetic Kidney Disease - FIGARO-DKD; Finerenone in Reducing Kidney Failure and Disease Progression in Diabetic Kidney Disease - FIDELIO-DKD; Heart Failure - HF; Transforming Growth Factor -TGF- $\beta$; Plasminogen Activator Inhibitor-type 1 - PAI-1; Extracellular Matrix - ECM; Miner Alocorticoid Receptor Antagonist Tolerability Study-Heart Failure - ARTS-HF; 


\section{Introduction}

The story of more than half of century of mineralocorticoid receptor antagonists (MRAs) began initially with 'aldosterone antagonists (AAs)' as the release of the first AAs during the 1950s being encouraged by identifying inhibitors aldosterone activity in animals and humans.

Two decades ago, the RALES study showed promising results of significantly declining mortality among patients in the spironolactone group, attributable to a lower risk of sudden cardiac death and death from progressive heart failure, the lower hospitalization rate for worsening heart failure, and a vital improvement in the symptoms of heart failure as assessed by the New York Heart Association functional class [1].

The positive results of RALES with spironolactone were followed by EPHESUS [2], and EMPHASIS-HF [3] where eplerenone consistently showed reduced morbidity and mortality in the investigated HF population.

Inappropriate activation of the mineralocorticoid receptor (MR) plays a significant role in developing hypertension, the development of cardiac pathological changes, and chronic kidney disease (CKD), where death related to cardiovascular (CV) causes is the primary competing the outcome to the progress to end-stage renal disease (ESRD) in patients with CKD [4].

Congestive heart failure (CHF) is a frequent comorbidity in patients with CKD. MR overactivation within the heart might cause coronary endothelial dysfunction, myocardial apoptosis, and reactive myocardial fibrosis and thus contribute to cardiac remodeling and its adverse consequences [5] MRAs are evidence-based therapy in symptomatic patients with heart failure and reduced ejection fraction (HFrEF) [6].

However, most supporting trials have excluded patients with renal dysfunction due to the high risk of hyperkalemia, especially when they are co-used with Angiotensin-converting enzyme inhibitors (ACE-i) and angiotensin receptor blockers. The risk for hyperkalemia was magnified several times in patients using both ACE-i and spironolactone versus ACE-i alone [7].

Widespread benefits with minimal side effects from using spironolactone in CKD patients have been repeatedly demonstrated where the increasing age [8] and the attendant decline in renal function [9] were independently associated with spironolactone-associated hyperkalemia.

It is more evident in diabetes mellitus, perhaps from a lack of insulin-driven intracellular transport of an acute $\mathrm{K}+$ load (10). This finding gets paramount importance counting the fact that diabetes is the leading cause of the end-stage renal disease (ESRD) [11] and both CKD and T2D are independently associated with HF [12].

This decline in GFR linked with inhibition of RAAS might not indicate an event of acute kidney injury and may be secondary to alterations in renal blood flow after reductions in blood pressure. The lack of progressive renal function decline after an initial worsening has been shown and holds this notion [13].

Nowadays, the third and fourth-generation MRAs like finerenone and esaxerenone that share a nonsteroidal structure is currently being evaluated in clinical trials opening a new chapter in treating heart failure in CKD and diabetic CKD patients.

Reports show higher potency and less hyperkalemia in finerenone compared with steroidal MRAs such as spironolactone and eplerenone due to the differential presence of the drug in the heart and kidney [14]. Finerenone overwhelms the inherent limitations of the steroidal MRAs. It has a higher selectivity towards mineralocorticoid receptor (MR) similar to spironolactone in one side and has a low affinity for androgen, glucocorticoid, and progesterone receptors eplerenone [15].

Apart from classical tissues, where MR activation stimulates renal sodium reabsorption and potassium excretion binding to the MR and controls sodium reabsorption and potassium secretion, MR expression has been specified in non-classical tissues, such as cardiomyocytes, endothelial, fibroblasts, vascular smooth muscle cells, adipocytes, and macrophages. In the last two decades, reports demonstrated a role for MR signaling in all-cause heart failure, disease settings in which tissue injury, oxidative stress, and inflammation were common factors [14].

Tissue injury and inflammation responses follow MR activation, resulting in diffuse interstitial and perivascular collagen depots representing established cardiac fibrosis. Aldosterone in the kidney and circulation enhanced Plasminogen activator inhibitor-1 levels, increasing so thrombosis and extracellular matrix accumulation. Besides, enhanced aldosterone was associated with the increased production of the profibrotic cytokine TGF- $\beta$.

On the other hand, aldosterone and TGF- $\beta 1$ counted together produced dramatic synergistic effects on PAI1 production and following ECM accumulation. Thus, activating the elevated aldosterone induced by the reninangiotensin-aldosterone system may strengthen reninangiotensin-aldosterone system profibrotic actions [16]. Beyond organ fibrosis, some reports showed that mineralocorticoid receptors significantly impact oxidative stress and inflammation.

Due to genomic and non-genomic effects, it is augmented reactive oxygen species (ROS) production (expressly by the enzyme NADPH oxidase), inflammation, and fibrosis, enabling tissue remodeling, vascular stiffening, and endothelial dysfunction mechanisms involved in hypertension and cardiac and kidney damage [17].

The expressed MR is present in macrophages and $\mathrm{T}$ cells, acting as an essential transcriptional cellular phenotype and function regulator. In pathological conditions, this is started even with normal or low aldosterone levels $[18,19]$. The anti-fibrotic effects of MR antagonists were evaluated in preclinical studies. MR antagonism was shown to decrease macrophage expression of the profibrotic genes tumor growth factor- $\beta 1$ and plasminogen activator inhibitor- 1 and 
increase anti-fibrotic gene expression [20].

Due to its nonsteroidal structure, the new generation, finerenone permits binding to the MR with higher affinity and inhibits recruitment of transcriptional coactivators involved in the expression of hypertrophic and profibrotic genes more effectively in comparison to the steroidal MRAs. Finerenone in models of cardiac fibrosis has shown qualitatively different effects on profibrotic gene expression and measures of inflammation and fibrosis compared with eplerenone [21, 22].

Besides, the nonsteroidal structure permits binding to the MR with high affinity and Inhibition of the recruitment of transcriptional coactivators involved in the expression of hypertrophic and profibrotic genes more effectively in comparison to the steroidal MRAs.

Finerenone has been investigated in different preclinical animal models of chronic hypertensive and ischemic heart and kidney diseases, which showed improved LV compliance and elastance when compared with infarcted control mice and reduced interstitial fibrosis [23].

Mulder et al. very nicely had demonstrated that finerenone improves diastolic function in a preclinical model of type-2 diabetes mellitus [24]. Preclinical heart failure animal models consistently have shown that finerenone exhibited an improved the therapeutic index compared to eplerenone in patients with HFrEF and concomitant T2DM and CKD [25].

The ARTS-HF Study was a randomized, double-blind, comparator-controlled, six parallel-group, multicenter phase $2 \mathrm{~b}$ dose-finding study in a high-risk population - at increased risk of post-discharge mortality and morbidity, on the one hand, and, on the other hand, prone to developing hyperkalemia and worsening renal function.

We recently have data of two large crucial trials that underline the impact of finerenone in $\mathrm{CV}$ among patients with T2DM and CKD [26, 27].

The FIGARO-DKD trial showed that finerenone has beneficial impacts on $\mathrm{CV}$ outcomes among patients with T2DM and CKD, who were in a maximal RAS blockade therapy setting, primarily due to a reduction in hospitalization for HF.

Reports pointed that both new-onset HF among patients without known HF was significantly declined with finerenone versus placebo (1.9\% vs. $2.8 \%$; HR $0.68,95 \%$ CI $0.50-0.93 ; \mathrm{p}=0.0162)$. Moreover, at the same time, a reduction of the time to hospitalization for $\mathrm{HF}$ or $\mathrm{CV}$ death was seen: $7.9 \%$ vs. $9.6 \%(p=0.011)$, [28].

In addition, the FIDELIO-DKD trial evaluated the effect of the nonsteroidal, selective mineralocorticoid receptor antagonist finerenone on kidney and cardiovascular outcomes in patients with chronic kidney disease and typed 2 diabetes with optimized renin-angiotensin system blockade.

It is found that among patients with chronic kidney disease and type 2 diabetes, finerenone reduced incidences of the composite cardiovascular outcome, with no evidence of differences in treatment effect based on preexisting CVD status [29].
Finerenone, a novel, nonsteroidal, selective mineralocorticoid receptor antagonist (MRA) with antiinflammatory and antifibrotic effects, is a promising tool in treating heart failure in patients with T2DM and CKD.

It is felt to have higher potency and less hyperkalemia than steroidal MRAs such as spironolactone and eplerenone. It is unclear and a matter of discussion if it could be a firstline therapy in this group of patients.

Conclusion: Nonsteroidal MRAs are currently tested in clinical trials. Based on preclinical and first clinical data, these nonsteroidal MRAs might overcome the limitations of today's steroidal antagonists.

\section{Declaration of Conflicting Interests and Ethics;}

The authors declare no conflict of interest. This research study complies with research publishing ethics. The scientific and legal responsibility for manuscripts published in Albanian Journal of Trauma and Emergency Surgery AJTES, belongs to the author(s).

Acknowledgements: None.

\section{References:}

1. Pitt B, Zannad F, Remme WJ, Cody R, Castaigne A, Perez A, Palensky J, Wittes J. The effect of spironolactone on morbidity and mortality in patients with severe heart failure. Randomized Aldactone Evaluation Study Investigators. N Engl J Med. 1999 Sep 2;341(10):709-17. DOI: 10.1056/ NEJM199909023411001. PMID: 10471456.

2. Pitt B, Williams G, Remme W, Martinez F, Lopez-Sendon J, Zannad $\mathrm{F}$ et al. Eplerenone, a selective aldosterone blocker, in patients with left ventricular dysfunction after myocardial infarction. N Engl J Med 2003; 348:1309-1321

3. Zannad F, McMurray JJ, Krum H, van Veldhuisen DJ, Swedberg K, Shi H et al. Eplerenone in patients with systolic heart failure and mild symptoms. N Engl J Med 2011; 364:1121.

4. Ruilope, L. M., Agarwal, R., Anker, S. D., Bakris, G. L., Filippatos, G., Nowack, C., Kolkhof, P., Joseph, A., Mentenich, N., Pitt, B., \& FIGARO-DKD study investigators. Design and Baseline Characteristics of the Finerenone in Reducing Cardiovascular Mortality and Morbidity in Diabetic Kidney Disease Trial. American journal of nephrology 2019; 50(5), 345-356. https://doi.org/10.1159/000503712.

5. Bauersachs J, Jasser F, Toto R. Mineralocorticoid receptor activation and mineralocorticoid receptor antagonist treatment in cardiac and renal diseases. Hypertension. 2015;65(2):25763.

6. Ponikowski P, Voors AA, Anker SD, Bueno H, Cleland JG, Coats AJ, et al. ESC Scientific Document Group 2016 ESC Guidelines for the diagnosis and treatment of acute and chronic heart failure the Task Force for the diagnosis and treatment of acute and chronic heart failure of the European Society of Cardiology (ESC)Developed with the special contribution of the Heart Failure Association (HFA) of the ESC. Eur Heart J. 2016;37(27):2129-200). 
7. MacFadyen RJ, Barr CS, Struthers AD. Aldosterone blockade reduces vascular collagen turnover, improves heart rate variability and reduces early morning rise in heart rate in heart failure patients. Cardiovasc Res. 1997;35(1):30-4.

8. Wrenger E, Müller R, Moesenthin M, et al. Interaction of spironolactone with ACE inhibitors or angiotensin receptor blockers: analysis of 44 cases. BMJ 2003; 327:147-9.

9. Ramadan FH, Masoodi N, El-Solh AA. Clinical factors associated with hyperkalemia in patients with congestive heart failure. J Clin Pharm Ther 2005; 30:233-9.

10. Vlassopoulos D, Sonikian M, Dardioti V, et al. Insulin and mineralocorticoids influence extrarenal potassium metabolism in chronic hemodialysis patients. Ren Fail 2001; 23:833-42.

11. 2018 USRDS Annual Data Report: Epidemiology of Kidney Disease in the United States (United States Renal Data System website). 2018.

12. Damman K, Testani JM. The kidney in heart failure: an update. Eur Heart J. 2015; 36:1437-1444. DOI: 10.1093/ eurheartj/ehv010.

13. Edwards NC, Steeds RP, Chue CD, et al. The safety and tolerability of spironolactone in patients with mild to moderate chronic kidney disease. Br J Clin Pharmacol 2012; 73:447-54.

14. Agarwal R, Kolkhof P, Bakris G, Bauersachs J, Haller H, Wada T, Zannad F. Steroidal and non-steroidal mineralocorticoid receptor antagonists in cardiorenal medicine. Eur Heart J. 2021;42(2):152-161.

15. Bramlage P, Swift SL, Thoenes $M$, et al. Nonsteroidal mineralocorticoid receptor antagonism for treating cardiovascular and renal disease. Eur J Heart Fail 2016; 18:28-37.

16. Huang W, Xu C, Kahng KW, Noble NA, Border WA, Huang Y. Aldosterone and TGF-beta1 synergistically increase PAI-1 and decrease matrix degradation in rat renal mesangial and fibroblast cells. Am J Physiol Renal Physiol. 2008;294(6): F1287-95. doi: 10.1152/ajprenal.00017.2008. PMID: 18367662 .

17. Briones AM, Touyz RM. Oxidative stress and hypertension: current concepts. Curr Hypertens Rep. 2010;12(2):135-42. doi: 10.1007/s11906-010-0100-z. PMID: 20424957.

18. Belden Z, Deiuliis JA, Dobre M, Rajagopalan S. The role of the mineralocorticoid receptor in inflammation: Focus on kidney and vasculature. American Journal of Nephrology. 2017;46(4):298-314.

19. van der Heijden CDCC, Deinum J, Joosten LAB, Netea MG, Riksen NP. The mineralocorticoid receptor as a modulator of innate immunity and atherosclerosis. Cardiovasc Res. 2018;114(7):944-953. doi: 10.1093/cvr/cvy092. PMID: 29668907.

20. Brown NJ. Contribution of aldosterone to cardiovascular and renal inflammation and fibrosis. Nat Rev Nephrol 2013; 9:459-469.
21. Kolkhof P, Delbeck M, Kretschmer A, Steinke W, Hartmann E, Bärfacker L, Eitner F, Albrecht-Küpper B, Schäfer S. Finerenone, a novel selective nonsteroidal mineralocorticoid receptor antagonist, protects from rat cardiorenal injury. J Cardiovasc Pharmacol 2014; 64:69-78.

22. Grune J, Beyhoff N, Smeir E, Chudek R, Blumrich A, Ban Z, Brix S, Betz IR, Schupp M, Foryst-Ludwig A, Klopfleisch R, Stawowy P, Houtman R, Kolkhof P, Kintscher U. Selective mineralocorticoid receptor cofactor modulation as molecular basis for finerenone's antifibrotic activity. Hypertension 2018; 71:599-608.

23. Gueret A, Haruki N, Favre J, Galmiche G, Nicol L, Henry JP, Besnier M, Thuillez C, Richard V, Kolkhof P, Mulder P, Jasser F, Ouvrard-Pascaud A. Vascular Smooth Muscle Mineralocorticoid Receptor Contributes to Coronary and Left Ventricular Dysfunction After Myocardial Infarction. Hypertension. 2016;67(4):717-23.

24. Mulder P, BarreraChimal J, El Moghrabi S, Kolkhof P, Ouvrard-Pascaud A, Jaisser F Finerenone improves diastolic function in a preclinical model of type 2 diabetes mellitus. Eur Heart J 2016; 37(Abstract Supplement):829

25. Kolkhof, Peter. [Handbook of Experimental Pharmacology] $\|$ Steroidal and Novel Nonsteroidal Mineralocorticoid Receptor Antagonists in Heart Failure and Cardiorenal Diseases: Comparison at Bench and Bedside.2016; (Chapter 76), doi:10.1007/164_2016_76.

26. Rico-Mesa, Juan Simon; White, Averi; Ahmadian-Tehrani, Ashkan; Anderson, Allen S. Mineralocorticoid Receptor Antagonists: a Comprehensive Review of Finerenone. Current Cardiology Reports 2020; 22(11), 140-148. doi:10.1007/ s11886-020-01399-7.

27. Filippatos G, Anker SD, Böhm M, Gheorghiade M, Køber L, Krum H, Maggioni AP, Ponikowski P, Voors AA, Zannad F, Kim SY, Nowack C, Palombo G, Kolkhof P, KimmeskampKirschbaum N, Pieper A, Pitt B. A randomized controlled study of finerenone vs. eplerenone in patients with worsening chronic heart failure and diabetes mellitus and/or chronic kidney disease. Eur Heart J. 2016;37(27):2105-14.

28. Filippatos G, Anker SD, Agarwal R, Ruilope LM, Rossing P, Bakris GL, Tasto C, Joseph A, Kolkhof P, Lage A, Pitt $\mathrm{B}$; FIGARO-DKD Investigators. Finerenone Reduces Risk of Incident Heart Failure in Patients With Chronic Kidney Disease and Type 2 Diabetes: Analyses from the FIGARO-DKD Trial. Circulation. 2021. doi: 10.1161/ CIRCULATIONAHA.121.057983. Epub ahead of print. PMID: 34775784.

29. Filippatos G, Anker SD, Agarwal R, Pitt B, Ruilope LM, Rossing P, Kolkhof P, Schloemer P, Tornus I, Joseph A, Bakris GL; FIDELIO-DKD Investigators. Finerenone and Cardiovascular Outcomes in Patients With Chronic Kidney Disease and Type 2 Diabetes. Circulation. 2021;143(6):540552. 